\title{
Assessing Self-rated Instruments to Detect Suicidal Thought among High School Students in Jakarta
}

\author{
Nova Riyanti Yusuf and Sabarinah
}

Faculty of Public Health, Universitas Indonesia, Depok, Indonesia

\section{Abstract}

The 2015 Global School-Based Student Health Survey revealed that suicidal thought in Junior and High school students was $4.3 \%$ in males and $5.9 \%$ in females. This harmful idea might be associated with an emotional problem in Jakarta. This study aimed to search validity of instrument measuring emotional problem in identifying suicidal thought, and the association of both problems. Secondary data analysis was conducted using survey result in one public and one vocational high school purposively chosen in 2015 by the Ministry of Health in South Jakarta. All students of the tenth and eleventh grade were assessed using self-rated of the Strengths and Difficulties Question (SDQ) to measure emotional problem, and Children's Depression Inventory (CDI) to detect potential depression including item asking suicidal thought. Analysis used criterion validity (sensitivity and specificity), and chi-square test. Respondents' gender was almost twice in male and averagely aged 15 years. SDQ screened suicidal thought had $35.2 \%$ sensitivity (95\%) $\mathrm{Cl} 28.5 \%-42.4 \%)$ and $85.6 \%$ specificity $(95 \% \mathrm{Cl} 82.8 \%-$ 88\%). Negative Predictive Value was $83.5 \%$ and Positive Predictive Value was $38.9 \%$ $(p=0.001)$. Overall, emotional problem was found in $20.51 \%$, potential depression was $30.39 \%$, and suicidal thought was $18.3 \%$.SDQ is specific but less sensitive in screening suicidal thought. Since suicidal thought in students of Jakarta was higher than the national figure, these self-rated instruments were strongly recommended utilized by the institution of high school in Jakarta in screening for a mental health problem.

Keywords: suicidal thought; high-school; Jakarta; SDQ; CDI.

\section{Introduction}

the responsibility of the 2 nd International Meeting of Public Health 2016 Conference Committee.

\section{S OPEN ACCESS}

Suicide is the third-highest cause of death among teens, resulting in 4,500 deaths per year in the United States. These risk factors are known as Mood Disorders and previous suicide attempts. Many researches that ave been done shows that there is an association between major depression and teen suicide (Nanayakkara 2013).

The World Health Organization estimates depression will be the second leading cause of disease by 2020 . Every year, over almost 800.000 people die from suicide 
-that's one person every 40 seconds. Suicide is the second leading cause of death in the 15 - 29 years' age group in 2012 globally (IASP 2016).

Researchers at Columbia University and other institutions confirmed in 1990 that suicide is contagious and can be transmitted between people. Contagion spreads either directly, by knowing a suicide victim, or indirectly, by learning of suicide through wordof-mouth or the media. People who know a suicide victim are almost twice as likely to develop suicidal thoughts as the general population. The anticipation of the role of media in the promotion of mental health has been emphasized in the Indonesian Mental Health Law Number 18 the Year 2014 (Yusuf 2014).

Those same researchers found that people ages 15 to 19 are two to four times more prone to suicide contagion than people in other age groups. The closer the relationship, the greater the risk; the younger the person exposed, the greater the risk.

The 2015 Global School-Based Student Health Survey in Indonesia revealed that suicidal thought in Junior and High school students was $4.3 \%$ in males and $5.9 \%$ in females. Percentage of High School students who made a plan about how they would attempt suicide by sex was 5.5 in males and 5.6 in females. Percentage of High School Students who attempted suicide by sex was 3.4 in females and 4.4 in males (Siswanto 2016).

Indonesia Health Survey 2013 also revealed the prevalence of suicidal thought in a population of $15+$ years old was 0.8 in males and 0,6 in females. The prevalence of suicidal thought in a population of 15+ years old in rural areas was 0.6 in male and 0.7 in females, while urban areas 0.7 in males and 0.9 in females. Based on the age group 15-25, 0.9 in females and 0.6 in males (Siswanto 2016).

In April 2016, the Directorate General of Disease Control and Prevention from The Health Ministry of the Republic of Indonesia reported the result of evaluating the characteristics of the psychometric questionnaire Services Evaluation on Mental Health Cases (EPK2J) with data collection conducted in four cities of Bali, Semarang, Yogyakarta, and Medan in October until November 2015. This research involved 502 respondents (The Health Ministry 2016).

In the suggestions and conclusions of the report, it explained if the items in the EPKJ2 questionnaire EPK2J will be used further, and the total score of the questionnaire will be used as an indicator to state that a person has a high or low tendency to commit suicide, it is advisable to conduct further studies to find strong evidence, both theoretically and empirically to show that the five dimensions consisting of 28 items to measure a person's tendency to commit suicide. The fifth dimension encompasses burdensomeness, belongingness, impulsiveness, loneliness, and hopelessness (The Health Ministry 2016). 
The EPKJ2 questionnaire being developed by the Health Ministry thus is not ready to be utilized to detect suicidal thought. It combines several instruments to meet the need for the Indonesian community while the urgency stated earlier in this background shows the importance of screening for suicidal thought among vulnerable groups, such as the age group of $15-29$ years old. The widely used instrument that will detect depressive symptoms with an item on suicidal thought is the Children's Depression Inventory. The screening for emotional problems is the Strengths and Difficulties Questionnaire. This study's objective is to search the validity of instruments measuring emotional problem in identifying suicidal thought, and the association of both problems.

\section{Methods}

\subsection{Participants and procedure}

For the purpose of this study, questionnaire data from 941 adolescents aged 13-18 years were used. Secondary data analysis was employed using survey result in one public and one vocational high school purposively taken in November - January 2015 by the Health Ministry in South Jakarta. All students of the tenth and eleventh grade were assessed using self-rated SDQ for measuring emotional problems that categorized into three groups, and CDI to detect potential depression including item asking suicidal thought. The questionnaire was administered during regular school hours with two researchers present throughout the survey process. The first section of the questionnaire asked adolescents to provide demographic information about their gender, age, and school.

The chosen public high school was a favorite public high school recently involved in a serious brawl, which caused death to a student. The chosen vocational school had been known for being bullied by other schools. (Tempo 2012)

Analysis used criterion validity (sensitivity and specificity), and chi-square test.

\subsection{Emotional problems}

Several screening instruments are available, and the instruments that can detect problems early and quickly have received special attention since the reducing of the impact and incidence of mental health problems need early detection. The SDQ has been translated into more than 60 languages and is widely used across different cultures. Thus SDQ is still a benchmark for screening in mental health problems among adolescents (Roy 2008; Silva 2015). 
The emotional problems were assessed with the Strength and Difficulties Questionnaire (SDQ), a 25-item 3-point scale (ranging from 0 to 2 ) scale measuring four difficulties (hyperactivity, emotional symptoms, conduct problems, and peer problems), as well as prosocial behavior. Each subscale had five items such as 'constantly fidgeting or squirming' (hyperactivity), 'many worries, often seems worried' (emotional symptoms), 'steals from home, school or elsewhere' (conduct problems), 'rather solitary, tends to play alone' (peer problem), and 'helpful if someone is hurt, upset or feeling ill' (prosocial behavior). A total difficulties scale was calculated by summing the scores for hyperactivity, emotional symptoms, conduct problems, and peer problems. Cut-off scores for the borderline/abnormal range (the SDQ cut-off score identifies $20 \%$ of the population) are $16+$ for total difficulties, $6+$ for emotional symptoms, 4+ for conduct problems, $6+$ for hyperactivity and $4+$ for peer problems, whereas the borderline/abnormal range for prosocial behavior was 0-5 (SDQ Info).

\subsection{Children's depression inventory (CDI)}

The Children's Depression Inventory (CDI) is one of the most widely used instruments in epidemiological studies to assess children and adolescents' self-report levels of depression, consisting of 27 items, each evaluated along a 3-point ordinal scale, for example for the item 'I am sad once in a while,' 'I am sad many times', and 'I am sad all the time', 0, 1, or 2 points are allocated according to a lower to higher depressive tendency for calculation of depression score. The 27 items include statements related to the following areas: sadness, pessimism, self-deprecation, anhedonia, misbehavior, pessimistic worrying, self-hate, self-blame, suicidal thought, crying spells, irritability, reduced social interest, indecisiveness, negative body image, school-work difficulty, sleep disturbance, fatigue, reduced appetite, somatic concerns, loneliness, school dislike, lack of friends, school performance decrement, self-depreciation (via peer comparison), feeling unloved, disobedience, and fighting. (Kovacs 1992). CDI is sensitive to changes in depressive symptoms over time and a Cut Off score of $>13$ as validated in Indonesia would be obtained as results that indicate the potential for depression.

\section{Results}

Respondents' gender was almost twice in male and averagely aged 15 years. All students of first and second grade, were almost similar in size per school. The majors in public school were natural sciences and social science, whilst the majors in vocational school were aviation and non-aviation. 
TABLE 1: Sociodemographic Characteristics.

\begin{tabular}{lll} 
Variables & Category & $\mathbf{n}(\%)$ \\
Sex & Male & $549(63.12)$ \\
& Female & $347(36.88)$ \\
Age & Mean (SD) & $15.55(0.73)$ \\
& Minimal & 13.00 \\
\hline School & Maximal & 18.00 \\
& Public & $432(45.91)$ \\
Major & Vocational & $509(54.09)$ \\
& Natural Sciences & $324(34.43)$ \\
& Social Sciences & $184(19.55)$ \\
& Aviation & $253(26.89)$ \\
& Non-Aviation & $180(19.13)$
\end{tabular}

Overall, the emotional problem was found in $20.51 \%$, potential depression (depressive symptoms) was $30.39 \%$, and suicidal thought was $18.6 \%$.

TABLE 2: Categories of Mental Problems.

\begin{tabular}{l|l|l} 
Variable & Category & $\mathbf{n}(\%)$ \\
CDI & No Depressive Symptoms & $65(69.71)$ \\
& Depressive Symptoms & $285(30.39)$ \\
SDQ & Normal & $748(79.49)$ \\
\hline \multirow{2}{*}{ Suicide } & Borderline + Abnormal & $193(20.51)$ \\
& I do not think of suicide & $759(80.66)$ \\
& I think of suicide and I want to kill myself & $175(18.60)$ \\
& Missing & $7(0.74)$
\end{tabular}

SDQ screening suicidal thought had $35.2 \%$ sensitivity (95\%) $\mathrm{Cl} 28.5 \%-42.4 \%$ ) and 85.6\% specificity (95\% Cl 82.8\% - 88\%). Negative Predictive Value was 83.5\% and Positive Predictive Value was $38.9 \%(p=0.001)$.

TABLE 3: Emotional Problem.

Emotional Problem
Borderline +
Abnormal
Normal
Total

Suicide
I think of suicide
and I want to kill
myself
68
107
175

\begin{tabular}{l} 
I do not think of \\
suicide \\
125 \\
\hline 634 \\
759 \\
\hline
\end{tabular}

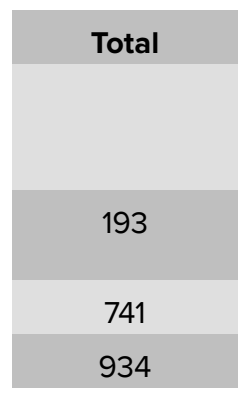


TABLE 4: Sensitivity, Specificity, NPV and PPV.

\begin{tabular}{|l|c|c|c|}
\hline Analysis & Value (\%) & \multicolumn{2}{|c|}{$95 \% \mathrm{Cl}$} \\
\hline Sensitivity & & Lower (\%) & Upper (\%) \\
\hline Specificity & 35.2 & 28.5 & 42.4 \\
\hline NPV & 85.6 & 82.8 & 88.0 \\
\hline PPV & 83.5 & 80.7 & 86.1 \\
\hline
\end{tabular}

\section{Discussion}

With lack of instrument availability to detect suicidal thought that is acceptable and appropriate for Indonesian community, the possibility is to do screening with the widely accepted instruments. SDQ and CDI are among the most validated and translated worldwide, including Indonesia. However, there has not been research to analyze correlation between SDQ screening results and suicidal thought in the CDI instrument, which is only one item in the CDI 27 items. SDQ is not only used to screen emotional problems but for this present study, it focuses on analyzing the emotional problems. CDI is used to assess the level of depression; thus it is more specific compared to SDQ which SDQ still also needs a follow-up interview using M.I.N.I KID Screen guideline to diagnose the mental disorder to those screened borderline or abnormal.

The result of NPV and PPV emphasized previous studies that supported the association between major depression and teen suicide. Although this study only focuses on suicidal thought and not the suicidal attempt.

Overall, emotional problem, potential depression (depressive symptoms), and suicidal thought in students of Jakarta were higher than national figure. This was a very harrowing fact. CDI and SDQ seemed to be very effective at this point, but the question remaining was if it would be enough for screening in Indonesia or the EPKJ2 questionnaire being developed in the Health Ministry needs to be continued.

\section{Conclusions}

SDQ is specific but less sensitive in screening suicidal thought. Since suicidal thought in students of Jakarta was higher than the national figure, these self-rated instruments were strongly recommended to be utilized by the institution of high school in Jakarta in screening for a mental health problem.

The future experiments must be able to formulate Suicide Risk Assessment for SchoolBased Mental Health and recommend a broader policy for National Suicide Prevention. 


\section{Acknowledgments}

The authors would like to acknowledge and thank all members of PITTA for the guidelines, opportunity, and support. We would also like to acknowledge the collaborative effort of continuing the MMHS program with Rusdy Syarief from Metaforma Institute as the owner of MMHS units and Dr Fidiansjah from the Health Ministry's Directorate of Prevention and Control of Mental Health and Narcotics Problems in funding the implementation. Lastly, the important discussions with Prof Dr Hasbullah Thabrany from Public Health University of Indonesia and Prof Byron Good from Harvard Medical School have strongly influenced this study.

\section{References}

[1] IASP - International Association for Suicide Prevention. 2016. World Suicide Prevention Day. http://www.iasp.info/wspd (accessed October 20, 2016)

[2] Kovacs, M. 1992. Children's Depression Inventory. North Tonawanda, NY: MultiHealth Systems, Inc.

[3] Nanayakkara, S, et al. 2013. Risk Factors: Depression and Exposure to Suicide Predict Suicide Attempt. Wiley Online Library.

[4] Roy, B.V., et.al. 2008. Construct validity of the five-factor Strengths and Difficulties Questionnaire (SDQ) in pre-, early, and late adolescence. The Journal of Child Psychology and Psychiatry, no.49:12: 1304 - 1312.

[5] SDQ Info. http://www.sdqinfo.com (accessed on October 15, 2016)

[6] Silva, T.B., et.al. 2015. SDQ: discriminative validity and diagnostic potential. Frontiers in Psychology.

[7] Siswanto. 2016. Challenges of Mental Health Research in Indonesia. Paper presented at the Workshop Research Capacity Building Towards the Implementation of National Institute of Mental Health in the World of Mental Health Day 2016 held by RSJ Dr Soeharto Heerdjan \& the Health Ministry, Jakarta.

[8] Tempo. 2012. http://m.tempo.co/read/news/2012/09/24/064431613/BeginiKronologi-Tawuran-Siswa-SMA-6-Versus-SMA-70 (accessed on October 20, 2016)

[9] The Health Ministry's Directorate General of Disease Control and Prevention. 2016. Report on the result of evaluating the characteristics of the psychometric questionnaire Services Evaluation on Mental Health Cases (EPK2J), Jakarta.

[10] Yusuf, N.R. 2014. A Rookie \& the Passage of the Mental Health Law: The Indonesian Story. Jakarta: Gramedia Pustaka Utama. 